\begin{tabular}{|l|l|}
\hline México y América Latina sujetos a la vulnerabilidad externa & Titulo \\
\hline Huerta González, Arturo - Autor/a; & Autor(es) \\
\hline $\begin{array}{l}\text { En: De Raíz Diversa. Revista Especializada en Estudios Latinoamericanos Vol. 1 no. } \\
\text { 2. (octubre-diciembre 2014). México : PPELA-UNAM, 2014. }\end{array}$ & En: \\
\hline México D.F. & Lugar \\
\hline $\begin{array}{l}\text { Programa de Posgrado en Estudios Latinoamericanos, Universidad Nacional } \\
\text { Autónoma de México }\end{array}$ & Editorial/Editor \\
\hline 2014 & Fecha \\
\hline $\begin{array}{l}\text { Vulnerabilidad económica; Distribución del ingreso; Desempleo; Macroeconomía; } \\
\text { Política; México; América Latina; }\end{array}$ & Colección \\
\hline Artículo & Temas \\
\hline "http://biblioteca.clacso.edu.ar/Mexico/ppel-unam/20160614033958/Huerta.pdr" & Tipo de documento \\
\hline $\begin{array}{l}\text { Reconocimiento-No Comercial-Sin Derivadas CC BY-NC-ND } \\
\text { http://creativecommons.org/licenses/by-nc-nd/2.0/deed.es }\end{array}$ & URL \\
\hline
\end{tabular}

Segui buscando en la Red de Bibliotecas Virtuales de CLACSO http://biblioteca.clacso.edu.ar

Consejo Latinoamericano de Ciencias Sociales (CLACSO)

Conselho Latino-americano de Ciências Sociais (CLACSO)

Latin American Council of Social Sciences (CLACSO)

www.clacso.edu.ar

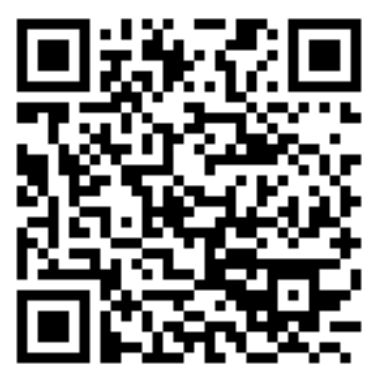




\section{México y América Latina sujetos a la vulnerabilidad externa}

Arturo Huerta GonzÁlez

RESUMEN. El presente trabajo analiza cómo la globalización y las políticas macroeconómicas de estabilidad que la acompañan le han quitado el control del dinero a los gobiernos, y por ende, el manejo de la política para configurar condiciones endógenas de acumulación y crecimiento. Las economías han pasado a depender de las variables externas. Los países que tienen ventajas comparativas en el sector primario han mostrado mayor crecimiento que el resto, aunque todos están sujetos al comportamiento del contexto internacional. Se analizan los problemas de crecimiento que enfrentan los países desarrollados y sus efectos en América Latina, que no tiene una política contracíclica para encarar los embates externos. Se plantea la necesidad de retomar el control de la moneda, así como de regular el sector externo y el financiero para poder flexibilizar la política económica a favor del sector productivo y del empleo, y de colocar el mercado interno como motor de crecimiento.

Palabras clave: Política macroeconómica, Vulnerabilidad externa, Desempleo, Distribución del ingreso.

Aвstract. This paper analyzes how the globalization process and the stability macroeconomic policies have removed the control of money from the government, and the consequent loss of control about the economic policy. This situation hampered the endogenous process of accumulation. Latin American economies are dependent on external variables. Countries with better comparative advantages in the agriculture and mineral sectors have grown more than the others; nonetheless all of them are vulnerable to the external shocks. They do not have anti-cycle policies to confront the external adversity. It is necessary to regain the control of the money, of the economic policy, in order to regulate the external and financial sector in favor of the productive sector, the employment and the internal market, diminishing the external vulnerability.

KEYWORDS: Macroeconomic policy, External vulnerability, Unemployment, Income distribution.

Recibido: 19 de noviembre de 2013. ACEPTAdo: 18 de marzo 2014.

\footnotetext{
* Profesor e investigador de la Facultad de Economía de la UNAM <ahuerta@unam.mx>
} 
1. LA GLOBALIZACIÓN OBLIGA AL PREDOMINIO DE POLÍTICAS DE ESTABILIDAD

$\mathrm{L}$

a libre movilidad de capitales obliga a establecer políticas de estabilidad macroeconómica para valorizar el capital del sector financiero, así como para desincentivar la salida de capitales y fomentar su entrada, por lo que predominan las altas tasas de interés, la disciplina fiscal, la estabilidad cambiaria y las reformas estructurales orientadas a promover entrada de capitales, necesarios para estabilizar la moneda.

La política de austeridad fiscal se encamina a reducir el déficit fiscal y el de comercio exterior, así como el monto de la deuda pública para promover la entrada de capitales que invierten donde el gobierno deja de hacerlo. Las políticas monetaria y fiscal restrictivas evitan presiones de demanda en los precios y aprecian la moneda, lo que abarata al dólar y el costo de los productos importados, logrando así la reducción de la inflación. Tal objetivo se alcanza a costa de actuar en detrimento de la competitividad de la producción nacional, lo que reduce las ganancias del sector productivo, acentúa la desindustrialización de las economías y aumenta el déficit de comercio exterior, lo cual genera problemas de sobreendeudamiento, que implica la transferencia creciente de recursos hacia la banca; esto descapitaliza más el sector productivo y se rezaga respecto al crecimiento del sector bancario-financiero, lo que configura el proceso de financiarización de las economías, que fragiliza su comportamiento.

Las propias políticas que buscan la estabilidad macroeconómica, al actuar en detrimento del sector productivo y del empleo, terminan presionando sobre las variables macroeconómicas que buscan estabilizar, llevando a la economía a depender de la entrada de capitales.

Las economías no tienen condiciones internas para viabilizar la operatividad de las políticas predominantes (liberalización económica y estabilidad macroeconómica), sino que descansan en requerimientos crecientes de entrada de capitales, lo que las coloca en un contexto de alta vulnerabilidad externa y obliga a que la política económica se dirija a promover entrada de capitales y relegue los objetivos de crecimiento.

\section{LA GLOBALIZACIÓN LE QUITÓ EL MONOPOLIO DEL DINERO A MUCHOS GOBIERNOS, LO QUE REDUCE SU TAMAÑO}

Las autonomías de los bancos centrales y las monedas únicas, en el caso de la zona euro, les han quitado a los gobiernos el control de la moneda. 
Al perder dicho control se deja de tener política económica a favor del crecimiento económico y del empleo, ya que se pasa a priorizar políticas de estabilidad monetaria-cambiaria a favor de quien controla la moneda, que es el sector financiero.

Los gobiernos de la zona euro han perdido poder con la Unión Monetaria Europea (UME); diez y siete países trabajan con una sola moneda, no la pueden emitir ni devaluar por sí solos. Una situación similar enfrentan la mayoría de los países latinoamericanos que se han comprometido a la estabilidad del tipo de cambio y a la convertibilidad de su moneda a dicho tipo de cambio, lo que los lleva a no tener una política monetaria ni cambiaria, por lo que dejan de tener una política fiscal a favor del crecimiento. Se ven obligados a establecer políticas de disciplina fiscal, por lo que dejan de satisfacer las demandas nacionales y amplían la participación de la cúpula empresarial en la economía.

Al no tener el gobierno el control de la moneda, tiene que trabajar con disciplina fiscal, por lo que predominan políticas contraccionistas y reformas estructurales de privatización y extranjerización que reducen el tamaño y participación del Estado en la economía. Las políticas no son neutras, responden a intereses de clase y el propósito de quitarle el monopolio del dinero al gobierno es para achicarlo y ampliar la participación de la cúpula empresarial en la economía.

\section{LAS POLÍTICAS DE LIBERALIZACIÓN ECONÓMICA Y LAS POLÍTICAS DE ESTABILIZACIÓN MACROECONÓMICA IMPIDEN POLÍTICAS CONTRACÍCLICAS, POR LO QUE LLEVAN A BAJAS TASAS DE CRECIMIENTO}

Los gobiernos han procedido a "liberalizar los mercados financieros en un esfuerzo de encarar las restricciones de liquidez interna" (Weller y Zulfigar, 2013); sin embargo, la política macroeconómica de estabilidad que acompaña dicho proceso acentúa más los problemas de acumulación interna y lleva a las economías a depender más de la entrada de capitales, los cuales fluyen para financiar los desequilibrios macroeconómicos que las políticas generan y no se canalizan a incrementar la inversión y la capacidad productiva.

Dicha política ha provocado cambios estructurales significativos reflejados en la desindustrialización, aumento de la economía informal, altos niveles de concentración del ingreso, presiones sobre el sector externo, altos niveles de endeudamiento, alta dependencia del comportamiento de 
las variables externas, así como pérdida de manejo soberano de la política económica, que han actuado en detrimento de la dinámica económica.

Al subordinarse la política fiscal a cumplir los objetivos de estabilidad del tipo de cambio y reducción de la inflación, deja de responder a los objetivos de pleno empleo, distribución del ingreso, crecimiento sostenido y otros objetivos socioeconómicos (Tcherneva, 2013).

$\mathrm{Al}$ seguir el bajo nivel de ingreso de la mayoría de los sectores productivos, sobre todo los no competitivos, dejan de ser sujetos de crédito, por lo que la empresa no tienen fondos internos ni externos para incrementar la inversión para modernizar el aparato productivo y aumentar la productividad, por lo que seguirán los problemas financieros, lo cual acentúa la desindustrialización y el bajo crecimiento de las economías.

Tal situación es insostenible, ya que las políticas predominantes presionan los desequilibrios antes mencionados y no configuran condiciones de reembolso de la deuda, por lo que continúa la restricción crediticia y el rezago al sector productivo, llevando a las economías a depender de las variables externas, colocándolas en un contexto de alta vulnerabilidad.

\section{LAS POLÍTICAS PREDOMINANTES NOS LLEVAN A DEPENDER DE LAS VARIABLES EXTERNAS}

La liberalización económica y la política macroeconómica de estabilidad que las acompañan han actuado contra las condiciones endógenas de acumulación, que han fragilizado las economías y las han llevado a depender del comportamiento de las variables externas, haciéndolas altamente vulnerables al acontecer internacional. Cualquier alteración del movimiento de mercancías y capitales trastoca la actividad económica.

Dependen de requerimientos crecientes de entrada de capitales para tener reservas internacionales que garanticen la estabilidad del tipo de cambio y la convertibilidad de la moneda a dicho tipo de cambio; esto lleva a que la política económica se dirija a la promoción de tales flujos de capital, para lo cual se mantienen altas tasas de interés, disciplina fiscal y reformas de privatización y extranjerización. Tales flujos son indispensables a su vez para financiar el libre movimiento de mercancías y capitales. Se viabiliza nuestra inserción en el proceso de globalización, se baja la inflación y estabiliza el tipo de cambio con políticas que promueven 
la entrada de capitales, a costa de sacrificar el crecimiento económico y de acelerar la extranjerización de las economías.

La apertura comercial generalizada predominante en la mayoría de los países, junto a la apreciación cambiaria, ha llevado a que el crecimiento de la demanda se filtre a importaciones y se presione la balanza del comercio exterior, lo que lleva a las economías a demandar entrada de capitales para su financiamiento, para lo cual se aumenta la tasa de interés y/o se impulsa la extranjerización de las economías. El problema es que la entrada de capitales mantiene apreciado el tipo de cambio, por lo que prosiguen la baja competitividad de las economías, así como las presiones en el sector externo y la baja dinámica económica, lo que repercute en problemas de insolvencia, además de mantener latente la demanda de entrada de capitales, y se cae en un círculo vicioso.

Las variables macroeconómicas son determinadas por el comportamiento de las variables externas (exportaciones, remesas y flujo de capitales), ya que muchas economías latinoamericanas no tienen condiciones endógenas para estabilizar el tipo de cambio y reducir la inflación.

$\mathrm{Al}$ actuar positivamente variables externas, se mejoran los términos de intercambio, como la posición de la balanza de pagos y se aprecia el tipo de cambio, que resta competitividad de sus productos, como del sector productivo, por lo que no se logra un crecimiento que se acerque al crecimiento potencial. Sin embargo, en muchos países las importaciones crecen en mayor medida que las exportaciones, y éstas, en el caso de las manufactureras, no tienen un fuerte efecto multiplicador interno dado su alto componente importado. Además, las importaciones desplazan a la producción nacional. Se dan rompimientos de cadenas productivas que aumentan el desempleo y subempleo de la economía, lo que contrae el mercado interno y hace a las economías más sujetas al comportamiento de las variables externas, por lo que aumenta su vulnerabilidad.

Muchas economías se están desindustrializando (véase el cuadro 1) como consecuencia de las políticas predominantes y de su falta de competitividad. En él podemos observar una drástica caída de la participación de la industria manufacturera en los últimos doce años en Brasil, Argentina y Perú. México mantiene su participación, pero muestra una desindustrialización en relación con los niveles alcanzados en 1980, donde dicha industria representaba $23 \%$ del PIB; en cambio, China sigue manifestando su poderío manufacturero. La desindustrialización presente tanto en países desarrollados como en 
desarrollo, ha llevado al avance del proceso de financiarización en tales economías.

Cuadro 1. Países seleccionados: Producción manufacturera, 2001-2012 (como porcentaje de PIB total)

\begin{tabular}{lccccc}
\hline Año/País & Brasil & Argentina & Perú & México & China \\
\hline 2001 & 17.0 & 23.5 & 16.0 & 18.4 & 32.9 \\
2002 & 16.6 & 23.9 & 15.9 & 17.8 & 32.7 \\
2003 & 16.7 & 23.6 & 14.0 & 17.8 & 32.3 \\
2004 & 16.2 & 22.7 & 14.4 & 18.1 & 29.5 \\
2005 & 14.6 & 22.6 & 14.0 & 18.1 & 30.7 \\
2006 & 13.3 & 21.7 & 14.6 & 18.3 & 31.4 \\
2007 & 17.0 & 23.5 & 16.0 & 18.4 & 32.9 \\
2008 & 16.6 & 23.9 & 15.9 & 17.8 & 32.7 \\
2009 & 16.7 & 23.6 & 14.0 & 17.8 & 32.3 \\
2010 & 16.2 & 22.7 & 14.4 & 18.1 & 29.5 \\
2011 & 14.6 & 22.6 & 14.0 & 18.1 & $\mathrm{n} / \mathrm{d}$ \\
2012 & 13.3 & 21.7 & n/d & 18.3 & n/d \\
\hline
\end{tabular}

Fuente: World Bank, databank, 2013.

\section{LOS PAÍSES DE AMÉRICA DEL SUR Y SU CRECIENTE RELACIÓN CON CHINA E INDIA}

El fuerte crecimiento de China, como el de otros países asiáticos e India, han favorecido las exportaciones de alimentos y minerales de varios países sudamericanos hacia dichos países, lo que ha favorecido su situación de balanza de comercio exterior y de crecimiento económico por varios años. Es decir, su dinámica se ha sustentado en el crecimiento de las exportaciones hacia tales países gracias a los recursos naturales con que cuentan y al alza de su precio internacional. En el cuadro 2 se muestran las altas tasas de crecimiento de las exportaciones a China de Brasil y Argentina en los últimos años, a excepción de 2009, año de crisis, donde Argentina enfrentó una fuerte caída. México es hasta 2010 cuando incrementa sus exportaciones petroleras a China. En el cuadro 3 se observa el crecimiento de las exportaciones agrícolas, mineras y de manufacturas de bienes intermedios de Perú de 2005 a 2010, que le ha permitido lograr altas tasas 
de crecimiento del PIB. Ha aprovechado sus ventajas comparativas y el alza de los precios internacionales para el impulso de las exportaciones y de la dinámica económica.

Cuadro 2. Paises seleccionados: Tasa de crecimiento de exportaciones a China, 2006-2010

\begin{tabular}{lccc}
\hline Año & Brasil & México & Argentina \\
\hline 2007 & 27.93 & 12.29 & 48.64 \\
2008 & 52.60 & 7.87 & 23.00 \\
2009 & 23.09 & 7.97 & -42.31 \\
2010 & 52.31 & 90.05 & 58.16 \\
\hline
\end{tabular}

Fuente: OCDE, 2013.

Al mejorarse los términos de intercambio, no solo crece el valor de las exportaciones y la dinámica de los sectores de exportaciones, sino que también se mejoran las finanzas públicas por los mayores ingresos tributarios derivados de las exportaciones, y más si estas están bajo el control del gobierno. Esto permite la expansión del gasto público, lo que incrementa la demanda y la actividad económica. Dependerá de tales recursos si incrementan la inversión y la esfera productiva nacional, si la dinámica lograda tiene o no mayor sostenibilidad o si continúa dependiendo exclusivamente de las exportaciones. Sin embargo, en muchos países los recursos derivados de las exportaciones no se han canalizado a apuntalar y diversificar la esfera productiva nacional. Al no potenciar su capacidad productiva y el crecimiento de su mercado interno, se han colocado en un contexto de alta vulnerabilidad en torno al comportamiento de las exportaciones, como del precio de los productos.

Al ir acompañado el crecimiento de exportaciones de alimentos y o minerales, y de entrada de capitales, se aprecia la moneda nacional, lo que resta competitividad a la producción manufacturera frente a las importaciones, por lo que se manifiesta un creciente déficit de comercio exterior manufacturero que tiende a contrarrestar el superávit de comercio exterior agrícola o primario, y a configurar un bajo crecimiento económico en tales economías. En el cuadro 4 muestra las variaciones del tipo de cambio nominal donde Brasil, Perú y China muestran apreciación de su moneda para tal periodo. En el caso de China, esto no ha afectado su competitividad dado 


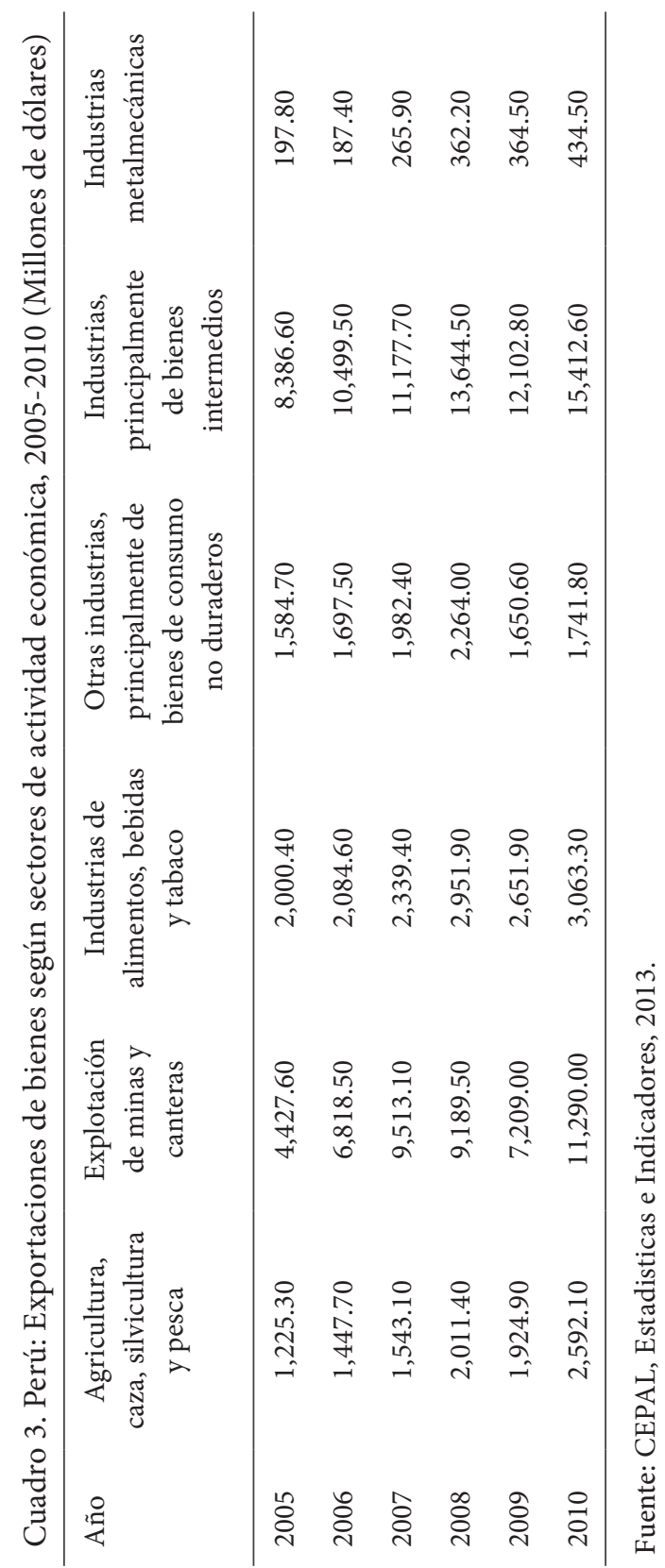


Cuadro 4. Paises seleccionados: Tipo de Cambio Nominal, 2007-2012 (moneda nacional por dólar)

\begin{tabular}{cccccc}
\hline Año & Argentina & Brasil & México & Perú & China \\
\hline 2007 & 3.10 & 1.95 & 10.93 & 3.13 & 7.60 \\
2008 & 3.14 & 1.83 & 11.13 & 2.92 & 7.00 \\
2009 & 3.71 & 2.00 & 13.51 & 3.01 & 6.80 \\
2010 & 3.90 & 1.76 & 12.64 & 2.83 & 6.80 \\
2011 & 4.11 & 1.67 & 12.42 & 2.75 & 6.50 \\
2012 & 4.54 & 1.95 & 13.17 & 2.65 & 6.30 \\
\hline
\end{tabular}

Fuente: CEPALESTAT, Bases de Datos, y OCDE 2013.

Cuadro 5. Países seleccionados: Balanza comercial de bienes manufactureros, 2006-2012 (Miles de millones de dólares)

\begin{tabular}{lcccccc}
\hline Año/País & Argentina & Brasil & China & México & México $^{*}$ & Perú \\
\hline 2006 & $-12,108$ & 1,576 & 388,038 & 19,823 & $-11,696$ & $-6,883$ \\
2007 & $-16,745$ & $-12,667$ & 542,440 & 17,515 & $-9,801$ & $-9,479$ \\
2008 & $-19,751$ & $-37,504$ & 690,132 & 20,229 & $-10,921$ & $-14,946$ \\
2009 & $-11,713$ & $-34,593$ & 522,771 & 12,911 & $-9,320$ & $-10,520$ \\
2010 & $-23,008$ & $-63,127$ & 676,217 & 22,209 & $-12,409$ & $-16,301$ \\
2011 & $-28,479$ & $-78,383$ & 859,256 & 14,374 & $-14,627$ & $-19,970$ \\
2012 & $-24,609$ & $-80,062$ & $1,015,758$ & 15,136 & $-18,691$ & $-21,922$ \\
\hline
\end{tabular}

Fuente: UNCTADstat, 2013.

* Excluyendo la maquila. 
el gran crecimiento de su productividad. A pesar de las variaciones nominales del tipo de cambio en México, su moneda se ha apreciado debido a que tal variación no incorpora el diferencial de la inflación y la productividad entre este país y Estados Unidos de América, que es su principal socio comercial. Argentina, ante la mala experiencia del Consejo Monetario en la década de los años noventa, donde ancló su moneda al dólar, ha venido trabajando con un tipo de cambio flexible que contribuye a mejorar su competitividad. En el cuadro 5 podemos ver los déficits del comercio exterior manufacturero creciente que se observa en Argentina, Brasil y Perú. México tiene un superávit en su balanza de comercio exterior manufacturero debido a la gran participación de las exportadoras de la industria maquiladora, si quitamos dicha industria, ya que es exportación de servicios de mano de obra, se tiene un déficit manufacturero. Por su parte, China ve casi triplicado su superávit de comercio exterior de 2006 a 2012 dada su fuerte posición competitiva a escala mundial. En el cuadro 6 podemos observar cómo Argentina, Brasil y Perú vieron duplicado su superávit de la balanza de comercio exterior de productos alimentarios de 2006 a 2012, y en cambio China y México son deficitarios.

Cuadro 6. Países seleccionados: Balanza comercial de productos alimenticios, 2006-2012 (Miles de millones de dólares)

\begin{tabular}{lccccc}
\hline Año/País & Argentina & Brasil & China & México & Perú \\
\hline 2006 & 20,025 & 30,208 & 6,686 & -41 & 2,164 \\
2007 & 26,803 & 36,427 & 2,672 & $-1,676$ & 1,966 \\
2008 & 34,837 & 46,823 & $-6,702$ & $-3,732$ & 2,345 \\
2009 & 26,205 & 45,162 & $-9,170$ & -218 & 2,289 \\
2010 & 32,447 & 52,423 & $-13,677$ & -721 & 2,724 \\
2011 & 42,625 & 67,293 & $-19,214$ & $-1,863$ & 3,810 \\
2012 & 40,814 & 66,893 & $-29,407$ & $-2,880$ & 4,711 \\
\hline
\end{tabular}

Fuente: UNCTADstat, 2013. 


\section{LAS ECONOMÍAS LATINOAMERICANAS ESTÁN SUJETAS AL COMPORTAMIENTO DE LA ECONOMÍA INTERNACIONAL}

Muchos países del área se han favorecido del crecimiento de las exportaciones alimentarias y de materias primas, tanto por el alza del precio de los productos, así como por los flujos de capitales que reciben de los diferenciales de interés existentes, lo cual les permite recibir parte de las inyecciones de liquidez llevada a cabo por la Reserva Federal a los mercados financieros estadounidenses.

La desaceleración de las economías desarrolladas reduce el crecimiento de los mercados de las exportaciones de los países en desarrollo, lo cual está afectando la dinámica de las economías que han venido creciendo en torno a sus exportaciones, como las llamadas economías BRIC, así como muchas otras economías. La caída de las exportaciones está llevando a decrecer el precio de las materias primas, alterando los términos de intercambio que les había favorecido, reduciendo el valor de las exportaciones de varios países latinoamericanos y presionando el sector externo, así como la dinámica económica. A esto se suma la salida de capitales que se deriva también de la posición de la Reserva Federal de dejar pronto la política de inyección de liquidez al mercado financiero de su país, lo que presiona la tasa de interés a largo plazo, lo cual incentiva el retorno de los capitales que habían fluido hacia las economías emergentes. Esto afecta el tipo de cambio y la tasa de interés de estas economías, aumentando el clima de incertidumbre.

$\mathrm{Al}$ actuar en forma adversa las variables externas que lo venían haciendo en forma positiva, se ha trastocado el comportamiento de las variables macroeconómicas, como el crecimiento económico, ya que se sustenta en las exportaciones, como en la entrada de capitales, evidenciando la alta vulnerabilidad en que han caído. Los problemas internos de las economías latinoamericanas afloran, ya que no hay capacidad productiva interna ni manejo soberano de la política económica para contrarrestar la caída del valor de sus exportaciones, como la salida de capitales.

La desaceleración del comercio mundial, a raíz de la contracción económica manifiesta en muchos países, está exacerbando la competencia en los mercados internacionales, lo que lleva a algunos a devaluar su moneda; los países que no pueden hacerlo están reduciendo salarios para mejorar la competitividad. Muchos países, al tener un déficit de comercio exterior creciente y al no tener políticas devaluatorias de ajuste y/o al no poder revisar su apertura 
comercial, optan por encarar el déficit de comercio exterior por medio de políticas restrictivas, como la entrada de capitales para financiarlo, por lo que tienen que mantener altas tasas de interés, como políticas de disciplina fiscal y venta de empresas y activos públicos. Esto tiende a mantener apreciado el tipo de cambio y atenta contra la esfera productiva, por lo que se contrae la competitividad y prosiguen las presiones en el déficit de comercio exterior, como las demandas de mayores créditos y de entrada de capitales, necesarios para financiar el déficit externo, como los déficits que están detrás de este.

Tienen que efectuarse contracciones drásticas de salarios y de la demanda para mejorar la competitividad y reducir las importaciones y el déficit de comercio exterior, lo que contrae el ingreso de empresas e individuos y mantiene latente el problema de insolvencia; este se recrudecerá ante la perspectiva del alza de la tasa de interés, ya que aumentará la carga del servicio de la deuda del sector público y privado, y lesionará sus finanzas, lo que afectará el funcionamiento del sector bancario-financiero, lo cual restringe la disponibilidad crediticia, repercutiendo en el consumo, la inversión y la dinámica económica.

El gobierno, por su parte, ve incrementado su déficit fiscal, sobre todo por la reducción de la recaudación tributaria, así como por el mayor costo de la deuda pública. De tal forma, la causalidad se da del déficit de comercio exterior al déficit fiscal (Nikifores et al., 2013). De ahí que las políticas de austeridad fiscal no logran reducir el déficit fiscal al persistir los problemas de competitividad, las presiones en la balanza de comercio exterior, así como los bajos niveles de ingreso de empresas e individuos, que mantienen latentes los problemas de insolvencia, la inestabilidad bancaria y la baja recaudación tributaria.

Hemos regresado a la situación que predominaba a principios del siglo $\mathrm{xx}$, que llevó a que la Gran Depresión (1929-1933) se generalizara a escala mundial. La historia se repite una y otra vez. Ahora con la desaceleración de la actividad económica de los países desarrollados, nuevamente se frena la actividad económica de América Latina, debido a que hemos pasado, otra vez a depender de las variables externas como consecuencia de la política macroeconómica de estabilidad predominante, por lo que al dejar de actuar tales variables positivamente, se desacelera la economía de los países latinoamericanos, en mayor o menor medida en función de los productos que exportan y de los márgenes de libertad que tienen las naciones para flexibilizar su política económica. Surge la pregunta: ¿América Latina tiene la capacidad de respuesta ante la eventual alza de la tasa de interés en Estados Unidos de América, como al menor crecimiento hacia fuera y al deterioro de los términos de intercambio? 


\section{DIFERENTES PERSPECTIVAS FRENTE A LA DESACELERACIÓN DE LA ECONOMÍA} MUNDIAL

La desaceleración de las economías desarrolladas está trastocando el funcionamiento de las economías emergentes, lo que pone en riesgo la estrategia de crecimiento hacia fuera, como el proseguir en el contexto de liberalización económica, debido a que no tienen un manejo de política económica para hacer frente a los problemas que la vulnerabilidad externa origina en sus economías.

Los países que exportan alimentos tienen mejor viabilidad de sortear la problemática mundial que los que exportan manufacturas, dado que los primeros son menos elásticos al ingreso que los productos manufacturados, por lo que caen menos al disminuirse la actividad económica de los países desarrollados.

Los países exportadores, como México, de manufacturas de bajo valor agregado nacional, cuya demanda enfrenta una alta elasticidad de ingreso al caer la dinámica de los países importadores, cae fuertemente la demanda, a diferencia de la demanda por granos básicos, que es más inelástica al ingreso, lo cual hace que la demanda y los precios no caigan tanto ante la desaceleración de los países importadores, por lo que su balanza de comercio exterior y su dinámica económica no se ven tan afectadas (UNCTAD, 2013: 60).

La UNCTAD señala que el precio internacional de los alimentos seguirá al alza, y más en el caso del maíz y del azúcar, que son utilizados en la producción de etanol y biodiesel. A su vez, las restricciones que enfrentan el crecimiento de la productividad y la producción mundial de alimentos contribuye al alza del precio de los mismos (UNCTAD, 2013: 57-58).

Tal situación actuará a favor de los países exportadores de los alimentos y afectará a los importadores, sobre todo si no tienen capacidad de exportación para financiar los requerimientos de importaciones. Países como Argentina y Brasil, exportadores de granos básicos, seguirán siendo beneficiados por el alza del precio de tales productos.

Los países exportadores de minerales, al ver reducida la demanda de sus productos y sus precios, ven afectada la balanza de comercio exterior, así como el crecimiento económico.

La dinámica de los exportadores de alimentos y minerales se vuelve dependiente de las perspectivas de crecimiento que tenga China e India. 
Si estas economías pueden retomar su crecimiento en torno al mercado interno, mantendrán la demanda de importaciones alimentarias y materias primas, lo que favorecerá el crecimiento de las exportaciones y la dinámica de los países latinoamericanos que exportan esos productos. Esto no garantiza un crecimiento sostenido, pues depende también del crecimiento de las importaciones. Si estas crecen más que sus exportaciones enfrentarán problemas de balanza de comercio exterior y de crecimiento.

\section{La PRoblemática Económica de los Países DesarRollados no Tiene Perspectivas de Superarse Pronto}

Los problemas de crecimiento de la zona euro no se superan y la economía estadounidense no repunta en los niveles esperados. Los rescates efectuados por los gobiernos y bancos centrales han sido a favor de los bancos, no del sector productivo ni de los desempleados y trabajadores. El sector financiero ha manifestado su poder para que se legislen y se instrumenten políticas a su favor, lo que le ha permitido recuperar y superar las pérdidas de 2008-2009, y retomar las prácticas de comportamiento que siempre ha tenido. La Banca ha recuperado sus ganancias a pesar que no presta. Las bolsas de valores a escala mundial han superado los niveles existentes antes de la crisis de 2008 y rompen récords a pesar de que la actividad económica no crece. En el cuadro 7 y la gráfica 1 se observa cómo el índice del Dow Jones en 2013 ha superado los niveles que tenía antes de la crisis de 2008, y el índice Nikkei se acerca a los niveles antes de la crisis. El sector financiero continúa sin ser regulado, lo que le permite mayores márgenes de acción para lucrar. Continúan manifestándose los diferenciales de crecimiento a favor del sector financiero y en detrimento del sector productivo, como consecuencia de que continúa la misma política económica a favor del primero.

A pesar de que el sector financiero ha recuperado sus ganancias y sigue siendo el sector hegemónico, continúa su disfuncionalidad en la dinámica económica. La financiarización de las economías nos lleva a recurrentes burbujas especulativas que terminan por caerse al cambiar las expectativas de la economía y al evidenciarse que no hay condiciones endógenas que las mantengan.

Los rescates del sector bancario se dirigen a la búsqueda de que encare sus obligaciones financieras y otorgue préstamos a empresas e individuos. 
Cuadro 7. Países seleccionados: evolución de la Bolsa de Valores, 2007-2013*

\begin{tabular}{lcc}
\hline Año & Japón (Nikkei) & $\begin{array}{c}\text { Estados Unidos } \\
\text { (Dow Jones) }\end{array}$ \\
\hline 2007 & $15,628.97$ & $13,314.57$ \\
2008 & $8,397.22$ & $8,149.09$ \\
2009 & $9,572.20$ & $10,471.58$ \\
2010 & $9,988.05$ & $11,255.78$ \\
2011 & $8,597.38$ & $12,020.03$ \\
2012 & $9,458.18$ & $12,965.60$ \\
2013 & $14,201.57$ & $15,615.55$ \\
\hline
\end{tabular}

Fuente: http://www.eleconomista.es

* 2013 contempla el cierre de noviembre del mismo año.

Gráfico 1. Países seleccionados: evolución de la Bolsa de Valores, 2007-2013*

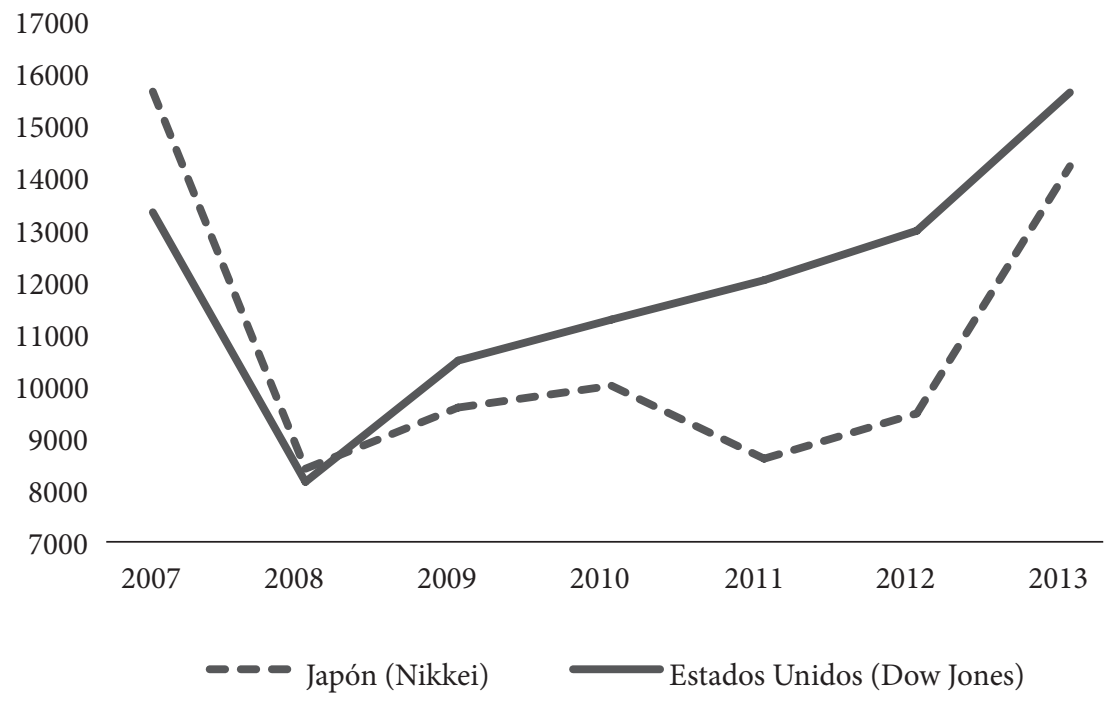

Fuente: http://www.eleconomista.es

* 2013 contempla el cierre de noviembre del mismo año. 
Esto último no se logra, dado que continúan los problemas de bajo crecimiento e insolvencia, que hacen que las empresas no demanden crédito y la banca no los otorgue, sino que canaliza los recursos a los mercados financieros.

Al seguirse relegando al sector productivo y la generación de empleo como consecuencia de la liberalización económica y de la política macroeconómica de estabilidad, así como por la incapacidad de la política económica para hacer frente a la vulnerabilidad externa la economía entra en recesión y no tiene condiciones de valorizar las ganancias que ofrece el sector financiero, ya que se reproducen los problemas de insolvencia que desestabilizan al sector bancario, lo que afecta a los mercados y a la economía en su conjunto.

Los problemas de la banca europea inciden en el sector bancario latinoamericano, pues este es controlado en gran medida por la banca de esos países. Se han hecho transferencias de recursos de los bancos con altas ganancias que operan en América Latina hacia la banca matriz que se encuentra por lo regular en España, lo que restringe más la disponibilidad crediticia hacia el sector productivo y frena el crecimiento.

Mientras sigan los altos niveles de endeudamiento y la política económica de la UME, no existen perspectivas de crecimiento ni de reducción del desempleo. La carga del servicio de la deuda, junto con la política de disciplina fiscal, de contracción del gasto e incremento de impuestos, y la desaceleración de las exportaciones, por la desaceleración de la economía mundial, proseguirá el contexto recesivo de las economías. El cuadro 8 y la gráfica 2 muestran las bajas y negativas tasas de crecimiento mostradas en algunos países de la zona euro a partir de la crisis manifiesta en 2008, que aún no ha sido superada. Los niveles de la actividad económica siguen por debajo de los existentes en 2007.

Ante la baja probabilidad de que los países desarrollados retomen su dinamismo, dado el predominio de las políticas fiscales restrictivas, no es de esperar que se recupere el crecimiento de las exportaciones manufactureras de países como México, que crece en función de esto, por lo que tenderá a manifestar bajas tasas de crecimiento, situación que obliga a buscar otros mercados para expandir las exportaciones, lo cual es difícil ante el recrudecimiento de la competencia en los mercados internacionales, que están llevando a algunos países a devaluar su moneda, generando una guerra de divisas, así como la reducción de salarios para mejorar la 
competitividad, configurando un proceso en el que es difícil salir victorioso, además que los bajos salarios restringen el crecimiento hacia el mercado interno.

Se ha caído en un contexto de bajo crecimiento de alta vulnerabilidad externa ante la incapacidad productiva para hacerle frente a los problemas venidos del exterior, como a la inexistencia de política económica contracíclica.

Cuadro 8. Eurozona: Tasa de crecimiento del PIB, 2007-2012

\begin{tabular}{lllllllll}
\hline Año & Alemania & Irlanda & Grecia & España & Francia & Italia & Chipre & Portugal \\
\hline 2007 & 3.3 & 5.4 & 3.5 & 3.5 & 2.3 & 1.7 & 5.1 & 2.4 \\
2008 & 1.1 & -2.1 & -0.2 & 0.9 & -0.1 & -1.2 & 3.6 & 0.0 \\
2009 & -5.1 & -5.5 & -3.1 & -3.7 & -3.1 & -5.5 & -1.9 & -2.9 \\
2010 & 4.2 & -0.8 & -4.9 & -0.3 & 1.7 & 1.7 & 1.3 & 1.9 \\
2011 & 3.0 & 1.4 & -7.1 & 0.4 & 1.7 & 0.4 & 0.5 & -1.6 \\
2012 & 0.7 & 0.9 & -6.4 & -1.4 & 0.0 & -2.4 & -2.4 & -3.2 \\
\hline
\end{tabular}

Fuente: Eurostat, database, 2013.

Gráfica 2. Eurozona: Tasa de crecimiento del PIB, 2007-2012

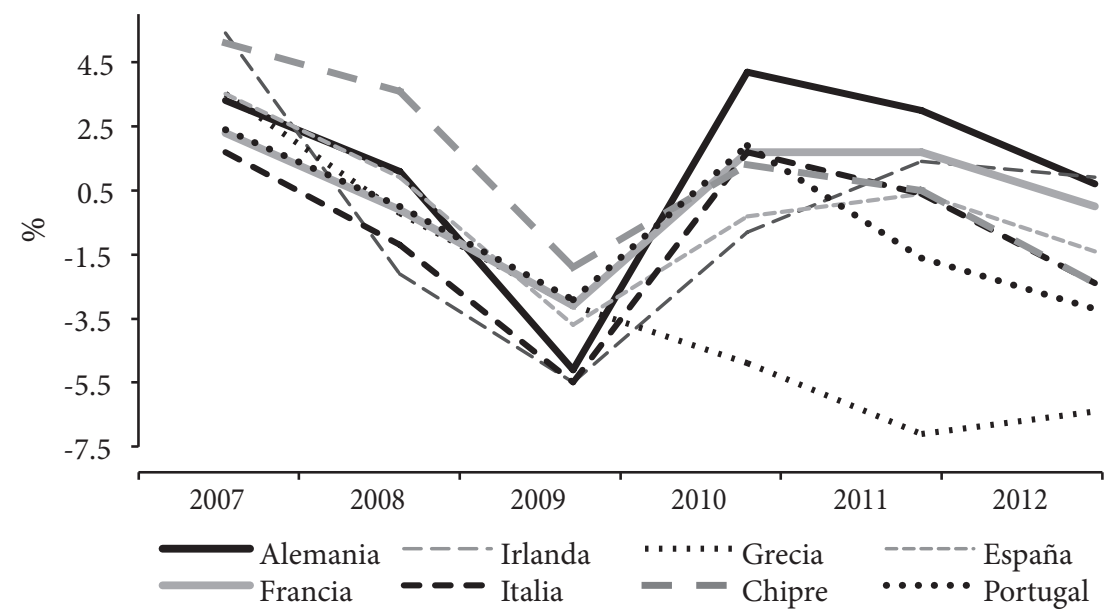

Fuente: Eurostat, database, 2013. 


\section{EL FRACASO DE LA FLEXIBILIDAD MONETARIA EN LOS PAÍSES} DESARROLLADOS PARA RETOMAR EL CRECIMIENTO

Las inyecciones de liquidez y la reducción de la tasa de interés que efectúa la Reserva Federal en Estados Unidos de América y el Banco Central Europeo, no han resultado efectivas para aumentar la disponibilidad crediticia, ya que no depende de las reservas bancarias, sino de la capacidad de reembolso de los deudores y sigue limitada debido a la predominante política fiscal restrictiva. Nos dice Wray que "los bancos no usan reservas para prestar" (2013).

El sector bancario restringe los créditos cuando el sector productivo tiene problemas de acumulación y de reembolso de la deuda. La contracción del crédito acelera la caída de la inversión, que ya venía dándose por la menor dinámica de acumulación en el sector productivo, de ahí que la acción del sector bancario amplifique la desaceleración de la dinámica del sector productivo.

La mayor disponibilidad crediticia para el sector privado no se expande si no tiene mayores ingresos y capacidad de pago, y para que estos ingresos crezcan es necesario que el gobierno trabaje con déficit fiscal y o que el sector externo sea superavitario. El problema es que el gobierno busca la disciplina fiscal y el sector externo es deficitario, y se enfrentan problemas para revertir tal situación ante la caída de exportaciones por la desaceleración de la actividad económica mundial. Al proseguir el bajo crecimiento económico, continuará la baja recaudación tributaria y las repercusiones en las finanzas públicas.

En vez de inyectar liquidez a la banca, que no la presta, sino la utiliza a favor de actividades especulativas, debería canalizarse a actividades productivas y a incrementar el empleo. En la época del New Deal, la Banca Central prestó directamente a grandes y pequeñas empresas (Greider, 2013). La banca central debe rescatar al sector productivo, no a la Banca.

El banco central tiene capacidad tanto para expandir la disponibilidad crediticia como para impulsar el empleo y la actividad económica mediante acciones directas (Greider, 2013), para lo cual es necesaria voluntad política. El banco central no necesita impuestos para gastar (Greider, 2013), para ampliar la liquidez y para expandir créditos. El límite es la inflación, por lo que tiene que canalizarse a favor del crecimiento de la productividad y capacidad productiva. 
10. NO HAY MANEJO MACROECONÓMICO EN LOS PAÍSES DE AMÉRICA LATINA PARA TENER CONDICIONES ENDÓGENAS DE CRECIMIENTO

La problemática económica internacional está derivando en la caída de exportaciones y remesas, así como de los precios de algunos productos de exportación, y en salidas de capitales ante la eventual alza de la tasa de interés en Estados Unidos de América, de muchos países latinoamericanos, lo cual recrudece los problemas del sector externo y frena la dinámica económica. En el cuadro 9 se observa cómo Argentina y Brasil crecían por arriba de México, debido a que han estado acompañando el dinamismo de China, dado el crecimiento de sus exportaciones hacia el país, y en 2012 vieron afectado su crecimiento ante la desaceleración de la nación oriental.

Ante esto, muchos países no tienen capacidad productiva interna ni manejo para flexibilizar la política para dinamizar el mercado interno y así contrarrestar los embates externos.

Cuadro 9. Países Seleccinados: Tasa de crecimiento anual del PIB, 2007-2012

\begin{tabular}{lccccc}
\hline Año & Perú & Brasil & Argentina & México & China \\
\hline 2007 & 8.91 & 6.10 & 8.65 & 3.26 & 14.20 \\
2008 & 9.80 & 5.17 & 6.76 & 1.19 & 9.60 \\
2009 & 0.86 & -0.33 & 0.85 & -5.95 & 9.20 \\
2010 & 8.76 & 7.53 & 9.16 & 5.28 & 10.40 \\
2011 & 6.86 & 2.73 & 8.87 & 3.89 & 9.30 \\
2012 & 6.28 & 0.87 & 1.90 & 3.92 & 7.80 \\
\hline
\end{tabular}

Fuente: Banco Mundial, banco de datos, 2013.

En el contexto de liberalización económica y efectos en la balanza de comercio exterior, las economías enfrentan problemas para tener una política monetaria, fiscal, cambiaria y crediticia contracíclica para encarar los embates externos.

No pueden flexibilizar la política económica ante el temor que implique un incremento de la demanda por liquidez y por divisas, lo que 
repercutirá en los precios, las reservas internacionales y la moneda, ya que el capital financiero requiere de la estabilidad de la moneda del país donde opera. El cuadro 10 y la gráfica 3 muestran el crecimiento de las reservas internacionales en Brasil, México y Perú, debido a que trabajan con un tipo de cambio estable y se han comprometido a la convertibilidad de la moneda a dicha paridad cambiaria. China es la economía con mayores reservas mundiales debido a su gran superávit de comercio exterior y su enorme entrada de capitales. Argentina, como trabaja con un tipo de cambio flexible, no tiene porqué incrementar sus reservas internacionales.

Se mantienen los precios macroeconómicos (tasa de interés y tipo de cambio) que actúan a favor del sector financiero y en detrimento del sector productivo, del crecimiento y del empleo, ya que continúa encarecido el crédito y el tipo de cambio apreciado que actúan contra la competitividad de la producción nacional, afectan la dinámica de acumulación de los sectores productivos y mantienen las presiones en la balanza de comercio exterior manufacturera y frenan el crecimiento. No bajan la tasa de interés en forma significativa ante el temor de que desestimule la entrada de capitales, provoque su salida y presione más al sector externo y el tipo de cambio. No se devalúa la moneda para mejorar la competitividad y contrarrestar la caída de exportaciones para impulsar la dinámica económica, ante el temor de que esto repercuta en los precios, afecte la valorización de la moneda y provoque una estampida de capitales. No pueden trabajar con un déficit fiscal para expandir la inversión y demanda interna y así evitar el aumento en los precios y el déficit de comercio exterior, lo cual pueda presionar el tipo de cambio.

Los países latinoamericanos siguen priorizando la estabilidad monetaria-cambiaria, por lo que no tienen viabilidad de flexibilizar su política económica y no pueden dinamizar su mercado interno para contrarrestar la caída de las exportaciones. Las economías se ven obligadas a mantener las políticas monetarias y fiscales restrictivas para no comprometer la estabilidad cambiaria.

Por lo tanto, no hay capacidad para aumentar la inversión e incrementar la capacidad productiva y la productividad para aumentar el valor agregado nacional de la producción y de las exportaciones, como para avanzar en la sustitución de importaciones y lograr una dinámica con menos repercusiones en el sector externo y más autosustentada. 
Cuadro 10. Países seleccionados: Reservas Internacionales ${ }^{*}$, 2007-2012 (Miles de millones de dólares)

\begin{tabular}{lccccc}
\hline Año & Argentina & Brasil & China & México & Perú \\
\hline 2007 & 46.15 & 180.33 & 1546.36 & 87.21 & 27.79 \\
2008 & 46.39 & 193.78 & 1966.04 & 95.30 & 31.24 \\
2009 & 48.01 & 238.54 & 2452.90 & 99.89 & 33.23 \\
2010 & 52.21 & 288.57 & 2913.71 & 120.58 & 44.21 \\
2011 & 46.27 & 352.01 & 3254.67 & 149.21 & 48.91 \\
2012 & 43.22 & 373.16 & 3387.51 & 167.08 & 64.16 \\
\hline
\end{tabular}

Fuente: World Bank, data bank, 2013.

* Reservas totales, incluye oro.

Gráfico 3. Países seleccionados: Reservas Internacionales, 2007-2012 (Millones de dólares)

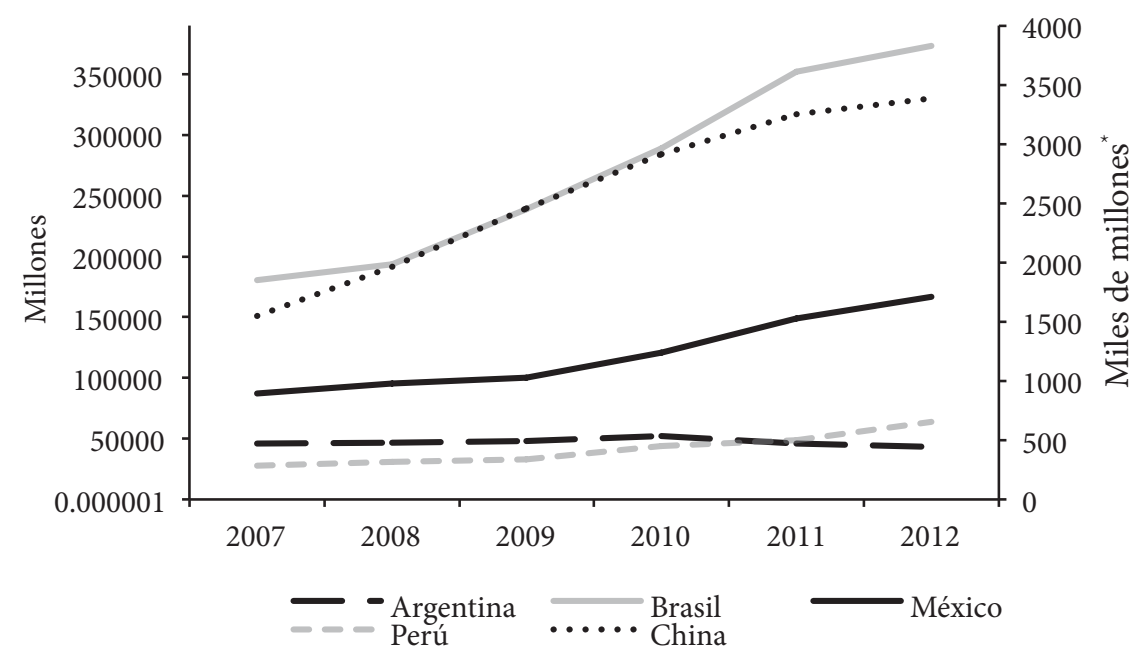

Fuente: World Bank, data bank, 2013.

* El eje secundario es únicamente para China. 
Al no tener control sobre la moneda, los gobiernos no pueden flexibilizar la política fiscal, sino que dependen de sus ingresos tributarios y no tributarios, que se ven contraídos tanto por el efecto negativo que tienen los embates externos en la actividad económica, actuando en consecuencia tanto la política de disciplina fiscal como la política procíclica.

La política de disciplina fiscal contrae la demanda, por lo que no genera condiciones endógenas de acumulación y crecimiento ni para aumentar el empleo y el ingreso de empresas e individuos, y con ello el consumo e inversión. Se mantienen latentes las presiones sobre el déficit de comercio exterior, así como los problemas de insolvencia, lo que mantiene restringido el crédito. Tal política fiscal aleja a la economía del crecimiento sostenido y la lleva a depender del comportamiento de las variables externas.

Hay quienes se oponen a que se flexibilice la política monetaria y fiscal ya que pudiera desestabilizar los mercados financieros, lo que según ellos provocaría el decaimiento del crecimiento y sufrirían los pobres (Rogoff, 2013); el autor añade que los controles a los mercados financieros y la represión financiera reducen la eficiencia en la asignación de los mercados de crédito. Sin embargo, no considera cómo la liberalización y desregulación de dicho sector ha favorecido la asignación de créditos hacia el propio sector financiero y ha actuado en detrimento del sector productivo.

Al no tener condiciones endógenas para hacer frente a los embates externos, algunos gobiernos, como el de México, aceleran las reformas de privatización y extranjerización de su economía para propiciar entrada de Inversión Extranjera Directa (IED) y así contrarrestar los embates externos. El cuadro 11 muestra el comportamiento de la IED en varios países. México muestra una tendencia decreciente, de ahí el propósito del gobierno de impulsar la reforma energética para abrir dicho sector a la inversión extranjera para estimular su entrada y contar con recursos para financiar la inserción de la economía en el proceso de globalización. Brasil tiene una creciente entrada de IED, al igual que Argentina y Perú. China es el país que mayor IED recibe en el mundo.

La entrada de capitales le permite financiar los desequilibrios macroeconómicos para mantener la liberalización económica y la estabilidad cambiaria, por lo que continúa la pérdida de competitividad, el bajo crecimiento y los bajos niveles de ingreso de empresas e individuos, los problemas de insolvencia y la restricción crediticia. 
Mientras sigan las reformas estructurales de extranjerización de sectores estratégicos, el capital seguirá fluyendo a estas economías. El problema se acentuará cuando cambien sus expectativas de comportamiento, tanto por el recrudecimiento de los problemas internos, como porque se agrave la problemática externa, lo que provocará una fuerte salida de capitales que contrarrestará su entrada, que desestabilizará la moneda, los mercados financieros y la economía.

Cuadro 11. Países seleccionados: Inversión Extranjera Directa*, 2007-2012 (Millones de dólares)

\begin{tabular}{cccccc}
\hline Año & Argentina & Brasil & México & Perú & China \\
\hline 2007 & $6,473.15$ & $44,579.49$ & $31,379.90$ & $5,490.96$ & $156,249.34$ \\
2008 & $9,725.56$ & $50,716.40$ & $27,853.34$ & $6,923.65$ & $171,534.65$ \\
2009 & $4,017.16$ & $31,480.93$ & $16,560.51$ & $6,430.65$ & $131,057.05$ \\
2010 & $7,848.30$ & $53,344.63$ & $21,372.42$ & $8,454.63$ & $243,703.43$ \\
2011 & $9,881.57$ & $71,538.66$ & $21,503.71$ & $8,232.64$ & $280,072.22$ \\
2012 & $12,551.12$ & $76,110.66$ & $12,659.43$ & $\mathrm{n} / \mathrm{d}$ & $253,474.94$ \\
\hline
\end{tabular}

Fuente: Banco Mundial, 2013.

* Inversión extranjera directa, neta (balanza de pagos, US\$ a precios actuales) n.d. no disponible.

Al recrudecerse los problemas de las economías latinoamericanas, el FMI no tendrá recursos suficientes para hacer frente a las demandas financieras y además no podrá seguir recomendando las mismas políticas que han estado presentes en la zona euro, y que desde hace décadas vienen predominando en los países latinoamericanos.

\section{EL CRECIENTE DESEMPLEO, SUBEMPLEO Y LA CAÍDA DE SALARIOS}

El desempleo, subempleo y la economía informal son funcionales al sistema imperante para debilitar la negociación de los trabajadores, reducir salarios y prestaciones laborales, y así bajar los costos de producción para mejorar la competitividad. Tal situación está presente en muchos países de la zona euro, así como en América Latina. Tratan de incrementar 
exportaciones para disminuir el déficit de comercio exterior y generar condiciones de reembolso, pero no lo logran del todo. Cuando los salarios bajan y aumenta el desempleo, se reduce la demanda, la inversión y el crecimiento.

Los bajos salarios y prestaciones, y el aumento de la participación del capital en el ingreso nacional, acentúa la mala distribución del ingreso que frena más el crecimiento de la actividad económica, debido a que los sectores de bajos ingresos que tienen alta propensión marginal a consumir (consumen casi todo su ingreso), al ver restringidos sus ingresos, contraen su consumo, la demanda, el mercado interno y la actividad económica, lo que genera un círculo vicioso, ya que aumenta el desempleo, se reducen más los salarios y las prestaciones laborales, lo que continúa contrayendo la demanda y la economía. Los países que enfrentan la caída del mercado interno y las exportaciones, están en el peor de los mundos posibles.

En el cuadro 12 se observa cómo las tasas de desempleo han disminuido en Brasil y Argentina, y cómo en Perú y México se ve incrementado el desempleo abierto. El cuadro 13 refleja que Perú y México presentan una economía informal muy superior a la de Argentina y Brasil. Los países que enfrentan relativas mejores condiciones laborales, tienen perspectivas de mantener cierto crecimiento en torno al mercado interno y con ello sortear la creciente vulnerabilidad externa.

Cuadro 12. Países seleccionados: Tasa media anual de desempleo, 2007-2012

\begin{tabular}{lcccc}
\hline Años & Argentina & Brasil & México & Perú \\
\hline 2007 & 8.5 & 9.3 & 4.8 & 8.4 \\
2008 & 7.9 & 7.9 & 4.9 & 8.4 \\
2009 & 8.7 & 8.1 & 6.7 & 8.4 \\
2010 & 7.7 & 6.7 & 6.4 & 7.9 \\
2011 & 7.2 & 6.0 & 6.0 & 7.7 \\
2012 & 7.2 & 5.5 & 5.9 & 6.8 \\
\hline
\end{tabular}

Fuente: CEPAL, Bases de Datos, 2013. 
Cuadro 13. Países seleccionados: Economía informal, 2012 (porcentaje de empleo)

\begin{tabular}{|c|c|}
\hline País/año & 2012 \\
\hline Brasil & 32.0 \\
\hline Argentina & 34.0 \\
\hline Perú & 68.6 \\
\hline México & 55.3 \\
\hline $\begin{array}{l}\text { Fuente: América economía, nota } \\
\text { (BRA). Comercio y justicia, nota } \\
\text { (ARG). IPS, nota periodística (ARG) } \\
\text { periodística (PER). La Prensa, nota } \\
\text { (PER). La Jornada, nota periodística } \\
\text { Economista, nota peridodística (MÉX) }\end{array}$ & $\begin{array}{l}\text { periodística } \\
\text { periodística } \\
\text { Perú21, nota } \\
\text { periodística } \\
\text { (MÉX). El } \\
\text { ). }\end{array}$ \\
\hline
\end{tabular}

\section{ES NECESARIO REDUCIR LA VULNERABILIDAD EXTERNA DE LAS ECONOMÍAS}

La desaceleración de las exportaciones, la salida de capitales y sus repercusiones en el tipo de cambio, obliga a algunos gobiernos a mantener la disciplina fiscal y la alta tasa de interés para frenar la salida de capitales. Esto restringe la demanda y aumenta el costo de la deuda, lo que tiende a frenar la inversión, el crecimiento económico y a recrear los problemas de insolvencia.

Para reducir la vulnerabilidad externa en que han caído las economías latinoamericanas, y ante la dificultad de que todos puedan sortear eficientemente tal situación, se necesita replantear la estrategia de crecimiento hacia afuera y encaminarse a una estrategia de crecimiento hacia adentro, lo que requiere a su vez el manejo soberano de la política macroeconómica para poderla flexibilizar a favor del crecimiento de la demanda, así como para reducir las afectaciones en el sector externo, para alcanzar condiciones de crecimiento sostenido.

Para la expansión del mercado interno es indispensable el gasto público deficitario, el incremento del empleo y de salarios, así como políticas proteccionistas, a fin de evitar filtraciones de demanda hacia el exterior; también es fundamental un fuerte crecimiento de la inversión productiva que impulse la sustitución de importaciones y el incremento de la capacidad productiva para satisfacer el crecimiento de demanda, para así 
evitar afectaciones en los precios y el sector externo que puedan frenar el crecimiento.

Para reducir la vulnerabilidad externa y retomar el manejo de la política económica a favor del crecimiento, es preferible controlar el movimiento de capitales, ya que su libre movimiento nos lleva a privilegiar políticas de estabilidad macroeconómica que actúan contra el crecimiento.

\section{LA POLÍTICA MACROECONÓMICA DEBE RESPONDER A FAVOR DE LO PRO- DUCTIVO Y DEL EMPLEO}

Para alcanzar un crecimiento autosostenido tiene que haber un manejo soberano de la política económica a favor del sector productivo, además de controlar al sector financiero y reducir las consecuencias en el sector externo. La regulación del sector financiero es para evitar burbujas especulativas y salidas de capitales que puedan trastocar la estabilidad macroeconómica, como la del sector financiero.

El enfoque convencional se opone al gasto público deficitario porque supuestamente genera un déficit de comercio exterior. Sin embargo, si se trabaja con un tipo de cambio flexible (competitivo), la devaluación mejoraría la competitividad y evitaría que la demanda se filtrara a las importaciones, lo que desencadenaría efectos positivos en el sector externo. La flexibilidad fiscal y cambiaria impulsarían la dinámica económica y reducirían los efectos en el sector externo; el problema es que el sector financiero se opone al déficit fiscal y a la devaluación de la moneda, ya que afectaría la valorización de su capital.

Cabe recordar que se salió de la gran depresión gracias al abandono del patrón oro, así como la devaluación del dólar, con cuotas a las importaciones y el aumento de tarifas, lo cual restringió importaciones y creó condiciones de rentabilidad para aumentar la producción manufacturera (UNCTAD, 2013:64).

Se tiene que dejar de priorizar la estabilidad del tipo de cambio para poder flexibilizar la política monetaria y fiscal a favor del crecimiento. Si la economía trabajara con un tipo de cambio flexible, en torno al movimiento de precios, y regulara el movimiento de mercancías y capitales, no tendría que instrumentar políticas restrictivas ni reformas de extranjerización de la economía. Es posible flexibilizar la política monetaria y fiscal para incrementar la productividad y la capacidad productiva, a fin de que 
esta acompañe el crecimiento de demanda derivada de dicho déficit y así evitar afectaciones de demanda en los precios e importaciones, como en el sector externo, que pueda repercutir en el tipo de cambio y frenar rápidamente el crecimiento.

La flexibilización del tipo de cambio permitiría tener una política contracíclica ante adversidades externas para tener un motor interno de crecimiento para mejorar el ingreso de empresas e individuos, y así, su capacidad de pago para asegurar la estabilidad del sector bancario para que este pueda flexibilizar los créditos a favor del sector productivo.

\section{PolíticA CONTRACÍCLICA A FAVOR DEL EMPLEO}

La política contracíclica no solo incrementa el gasto y la demanda para contrarrestar la caída de las exportaciones y del consumo e inversión del sector privado, sino que también se dirige a generar empleo y mejorar el ingreso del sector más pobre de la población (Tcherneva, 2013); la autora nos dice que la política fiscal, más que favorecer la demanda para la producción y las ganancias, debe impulsar la demanda de empleo y los salarios. En vez de priorizar el crecimiento, debe tener como objetivo el empleo (Tcherneva, 2013); también nos indica que el crecimiento comúnmente beneficia a los trabajadores bien calificados y de alto salario, y no a los de bajo salario, lo que mantiene la alta concentración del ingreso, y de ahí la necesidad de que la política ponga en el centro el empleo. Debe ser una política a favor del empleo, para lo cual se debe tener un manejo soberano de la política económica para propiciar un cambio estructural a favor de la esfera productiva y que redistribuya el ingreso, para lo cual debe regular y subordinar al sector financiero hacia tales objetivos.

La política fiscal debe encaminarse a incrementar el gasto aprovechando la capacidad ociosa para incrementar la capacidad productiva y el empleo, dirigido a satisfacer las demandas de la población (Tcherneva, 2013).

Hemos dicho que la política fiscal debe trabajar en función del desempeño del consumo, la inversión y las exportaciones. Si estas variables actúan en forma negativa, el gobierno debe trabajar con el gasto deficitario para contrarrestar la caída de las variables y así evitar la desaceleración de la actividad económica. Si la economía enfrenta un déficit de comercio exterior y el sector privado está contrayendo consumo e inversión para pagar su deuda, el déficit del gobierno debe encaminarse a reducir el 
déficit externo y a mejorar las finanzas del sector privado para mantener la dinámica económica. Siguiendo a Kalecki, Sawyer nos dice que el déficit fiscal es igual a la suma del ahorro menos la inversión, más el déficit de cuenta corriente (2010).

Para impulsar el crecimiento del empleo es indispensable que el gobierno desempeñe un papel importante mediante el gasto público deficitario a favor de la producción nacional, como incentivando la inversión privada y distribuyendo el ingreso (Kalecki, 1944).

\section{DISPONIBILIDAD CREDITICIA EN FUNCIÓN DE LAS CONDICIONES DE REEMBOLSO}

Para que se expanda el crédito a favor del crecimiento de la inversión, el sector productivo tiene que ofrecer condiciones de crecimiento y reembolso, por lo que la expansión de liquidez y la menor tasa de interés tiene que ir acompañada de políticas de expansión fiscal que aumente la demanda y el empleo (Greider, 2013).

Al retomar la actividad económica, se incrementaría el ingreso de empresas e individuos que podrían pagar sus deudas para que la banca vuelva a brindar crédito, ya que se mejorarían las condiciones de reembolso de la deuda. Nos dicen Pérez y Titelman que "el sistema financiero tiende a actuar como un amplificador de las fluctuaciones reales y las recuperaciones reales ocurren antes de la recuperación del crédito" (2013). La expansión del crédito da lugar a que se potencie el crecimiento de la inversión, del consumo y de la actividad económica, y al tener esta un alto efecto multiplicador interno, se retroalimentaría dicho proceso.

\section{NECESIDAD DE TENER EL CONTROL DE LA MONEDA}

El déficit fiscal y la deuda pública en moneda nacional son sostenibles si el gobierno tiene control de la moneda y si no se compromete la estabilidad nominal del tipo de cambio. Esto permite monetizar la deuda, lo cual no originaría presiones inflacionarias si el gasto deficitario se canaliza a incrementar la productividad y la capacidad productiva.

La política monetaria tiene que acompañar a la política fiscal, y no a la inversa como ha sucedido. Hasta ahora la política fiscal se subordina a los 
objetivos del banco central de estabilidad cambiaria y reducción de la inflación, por lo que se trabaja con la disciplina fiscal. La política fiscal debe actuar a favor del crecimiento y del empleo, para lo cual debe expandir el gasto público, y la política monetaria debe acompañar dicho proceso, generando la liquidez necesaria para viabilizarlo. La emisión de deuda del gobierno será para regular la liquidez generada para evitar presiones inflacionarias o que se especule con el dinero. Como dice Lerner:

Se emiten bonos cuando el gobierno quiere que la gente tenga menos efectivo en su poder. En un país donde hay necesidades masivas no satisfechas, recursos y gente desempleada, y oportunidades abundantes para crear nuevos valores, nuevos mercados[...] el sector privado debe ser capaz de absorber nuevo dinero vía gasto directo sin desestabilizar precios (1943).

\section{CONTROL DEL MOVIMIENTO DE MERCANCÍAS Y CAPITALES PARA FLEXIBILI- ZAR LA POLÍTICA ECONÓMICA}

Cuando una economía enfrenta un déficit de comercio exterior, es reflejo de que las importaciones desplazan a la producción nacional del mercado interno, lo que frena las ganancias de este sector, llevándolo a reducir su inversión y la actividad económica. Para contrarrestar tal situación, el gobierno debería trabajar con gasto público deficitario y evitar que el incremento de demanda generado se filtre hacia importaciones, ya sea mediante un tipo de cambio flexible (competitivo), como con políticas proteccionistas, pero esto no es lo que predomina en la mayoría de los países de América Latina, sino todo lo contrario, la disciplina fiscal, la apreciación cambiaria y la apertura generalizada actúan en detrimento del sector productivo y del empleo.

Para tener una política a favor del sector productivo se tiene que regular el movimiento de mercancías, al sector financiero y el movimiento de capitales para evitar filtraciones de demanda, de capitales y prácticas especulativas, así como repercusiones en el déficit de comercio exterior y la balanza de pagos, para que no se frene la actividad económica ni se desestabilice el tipo de cambio.

Hay que acortar los diferenciales de ganancia entre el sector productivo y el financiero, a fin de revertir el proceso de financiarización que ha predominado en las últimas décadas, para alcanzar un mejor vínculo 
entre los sectores productivo y financiero. Esto también sucede al regular el movimiento de mercancías.

$\mathrm{Al}$ impulsarse la dinámica económica y al tener esta altos efectos multiplicadores internos, se incrementará el ingreso de empresas e individuos y del gobierno, lo que mejorará las finanzas de estos sectores y su capacidad del pago de la deuda, como la relación de endeudamiento, y será necesaria una menor participación activa del gobierno (gasto deficitario) para mantener el dinamismo, ya que este sería impulsado con el consumo e inversión del sector privado.

Es importante mantener la dinámica de exportaciones y aumentar su valor agregado nacional para generar las divisas necesarias para financiar las importaciones suficientes para evitar el déficit de comercio exterior y alcanzar un crecimiento económico sostenido.

\section{POLÍTICA DE DISTRIBUCIÓN DEL INGRESO Y DE INCREMENTO DE LA PRODUCTIVIDAD}

Hay que redistribuir el ingreso para incrementar la demanda, y en consecuencia, la actividad productiva y el empleo. Una política tributaria que grave los sectores más ricos, no afecta la inversión ni su consumo dada la baja propensión marginal a consumir que tienen, ni frena la actividad económica. Si los recursos que le quitan a tal sector se canalizan para mejorar el ingreso y el poder de compra de los que menos tienen, se incrementa la demanda y la actividad económica, dada la alta propensión a consumir de los sectores de bajos ingresos. Se puede reactivar la actividad económica al redistribuir el ingreso sin necesidad de recurrir al déficit público.

La política de distribución del ingreso para dinamizar el mercado interno requiere del incremento de la productividad y de la producción agrícola, así como de los bienes de consumo salarial, lo que demanda una política agrícola e industrial. Esto pasa por asegurar condiciones de rentabilidad en los sectores para impulsar la inversión y modernización, para lo cual, además de políticas de subsidios a favor de la producción de los bienes, se demandan políticas devaluatorias y proteccionistas para evitar competencia desleal que pueda mermar las ganancias y decisiones de inversión de los productores internos de estos bienes.

De no atacar la mala distribución del ingreso existente en la mayoría de los países y de seguir la política de disciplina fiscal continuará el bajo crecimiento de la actividad económica y el alto desempleo. 


\section{BIBLIOGRAFÍA}

GREIDER, W. (2013); Unusual and Exigent: How the Fed Can Jump-start the Real Economy en Levy Economics, Institute of Bard College, Policy Note 2013/8.

KALECKI, M. (1944); Three ways to full employment en The economics of full employment, Oxford: Blackmel.

LERNER, A. (1943); Funcional finance and federal debt en Social Research 10(1).

NIKIFORES, M. et al., (2013); Foreign and Public Deficits in Greece en Levy Economics, Institute of Bard College, Working Paper núm. 771.

PÉREZ, E. y D. TITELMAN, (2013); Macroeconomics for Development in Latin America and the Caribbean: Some new considerations on countercyclicality, artículo presentado en la CEPAL, Seminar on Neo-Structuralism and Heterodox economics, pp. 22-23.

ROGOFF, K. (2013); ¿Están sumergiéndose los mercados emergentes? en El País, 22 de septiembre. Madrid.

SAWYER, M. (2010); Progressive approches to budget deficits en Stabilising an unequal economy? Public debt, financial regulation and income distribution, O. Onaran et al. (edit), Metropolis Verlag.

TCHERNEVA, P. (2013); Reorienting Fiscal Policy en Levy Economics, Institute of Bard College, Working Paper núm. 772.

UNCTAD, (2013); Trade Development Report, Geneva, United Nations.

WELLER, Ch. y ZULFIJAR, G. (2013); Financial Market Diversity and Macroeconomics Stability en Political Economy Research, Institute of University of Massachusetts Amherst.

WRAY, R., (2013); Banks Don't Lend Reserves en EcoMonitor, Economics for the $21^{\text {st }}$. Century and Beyond. 